\title{
Gastric mucosal protection with selective inhibition of thromboxane synthesis
}

\author{
R P WALT, R T KEMP, B FILIPOWICZ, J G DAVIES, N K BHASKAR, \\ AND C J HAWKEY
}

From the Department of Therapeutics, University Hospital, Nottingham

SUMMARY Because thromboxane synthesis enhances gastric mucosal damage we have investigated whether the thromboxane synthesis inhibitor dazmegrel might be protective to the mucosa. Dazmegrel at a dose of 1 and $5 \mathrm{mg}$ per rat $(4.8$ and $23.8 \mathrm{mg} / \mathrm{kg})$ significantly reduced the damage caused by acidified taurocholate. In parallel experiments dazmegrel exerted a selective and dose dependent inhibition of ex vivo thromboxane synthesis by gastric fragments over the dose range in which protection was observed. As dazmegrel can be given to man, these experiments suggest that investigation of mucosal protection would be justified.

At present there is considerable interest in the use of prostaglandins to treat peptic ulceration and in the role of 'cytoprotection' of the gastroduodenal mucosa in this process.' Exogenous prostaglandins can prevent or limit gastric mucosal damage provoked by ethanol, bile acids and non-steroidal anti inflammatory drugs in the rat ${ }^{\prime 2}$ and there are more limited comparable data in man.' There is growing evidence that similar protection can be achieved by stimulating endogenous prostaglandin synthesis. ${ }^{3-5}$

In contrast with the $E$ and I prostaglandins, thromboxane $\mathrm{A}_{2}$ has properties which can be detrimental to gastric mucosal integrity. Thromboxane $A_{2}$ is vasoconstrictor and enhanced synthesis produced by continuous infusion of arachidonic acid causes the rapid development of extensive gastric erosions in chambered rat stomachs exposed to acidified taurocholate. "This damage could be prevented by the use of benzyl imidazole, a thromboxane synthethase inhibitor. We have therefore investigated the protective potential of dazmegrel (Fig. 1), another thromboxane synthethase inhibitor available for human use ${ }^{7-9}$ in a different model of gastric mucosal damage, and have defined its effects on synthesis of $\mathrm{TXB}_{2}$ and $\mathrm{PGE}_{2}$ in gastric mucosa.

Address for correspondence: Dr C J Hawkey, Department of Therapeutics. Floor C. South Block. University Hospital, Nottingham NG7 2UH. Received for publication I September 1986.

\section{Methods}

\section{MATERIALS}

Dazmegrel (3-(-IH-imidazol-l-yl-methyl)-2-methylIH-indole-1-propanoic acid, MW283) was supplied by Pfizer UK Ltd and used at three concentrations $(2 \mathrm{mg} / \mathrm{ml}, 10 \mathrm{mg} / \mathrm{ml}$, and $50 \mathrm{mg} / \mathrm{ml})$ in phosphate buffered saline (PBS), $0.05 \mathrm{M} \mathrm{pH} \mathrm{7.4.}$

Prostaglandin $\mathrm{E}_{1}$ was supplied by Upjohn, Kalamazoo and made up to $150 \mathrm{mg} / \mathrm{ml}$ in PBS from ethanolic stock solutions $(1 \mathrm{mg} / \mathrm{ml})$. Sodium taurocholate (Sigma UK) was dissolved in $0.2 \mathrm{~N}$ hydrochloric acid to a final concentration of $100 \mathrm{mM}$. All solutions were freshly prepared immediately before the start of each experiment and coded to ensure that the investigator was unaware of their identities.

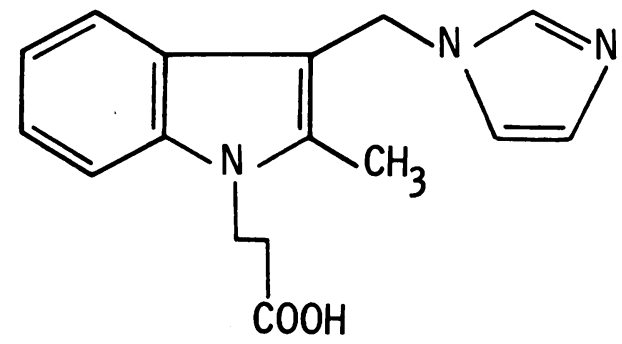

Fig. 1 Chemical structure of dazmegrel (molecular weight 283). 
Male Wistar rats weighing between 200 and $220 \mathrm{~g}$ were used in all experiments. The rats were housed in restraining cages to prevent coprophagy, were fasted for 20 hours and were deprived of water for four hours before each group of experiments.

\section{GASTRIC MUCOSAL DAMAGE}

Groups of rats were treated as shown in Figure 2. Dazmegrel in PBS or PBS alone were administered by gavage in volumes of $0.5 \mathrm{ml}$ through a 5 FG orogastric tube. Three doses of dazmegrel were used, $1 \mathrm{mg} / \mathrm{rat}(4.8 \mathrm{mg} / \mathrm{kg}, \mathrm{n}=8), 5 \mathrm{mg} / \mathrm{rat}(23.8 \mathrm{mg} / \mathrm{kg}$, $\mathrm{n}=8)$ and $25 \mathrm{mg} / \mathrm{rat}(119 \mathrm{mg} / \mathrm{kg}, \mathrm{n}=8)$. Two hours later $1 \mathrm{ml}$ acidified taurocholate or distilled water was administered by gavage and after a further hour the animals were killed by $\mathrm{CO}_{2}$ narcosis. Seven rats were pretreated with $\mathrm{PGE}_{1}, 75 \mu \mathrm{g}$ in $0.5 \mathrm{ml}$ PBS 15 minutes before acidified taurocholate and killed one hour later. In each experiment positive control (PBS followed by taurocholate) and negative controls (PBS followed by water) were included.

\section{ASSESSMENT OF DAMAGE}

After death the stomachs were carefully removed, and opened along the greater curve, and flattened on glass. Damage was assessed by two observers independently, using a numerical grading score of $0-4$. Grade 0 was no macroscopic abnormality, grade 1 a few spots of mucosal haemorrhage, grade 2 spots of mucosal haemorrhage with short confluent streaks, grade 3 long confluent streaks of mucosal haemorrhage, grade 4 confluent streaks of mucosal haemorrhage with surface blood. The assessors were

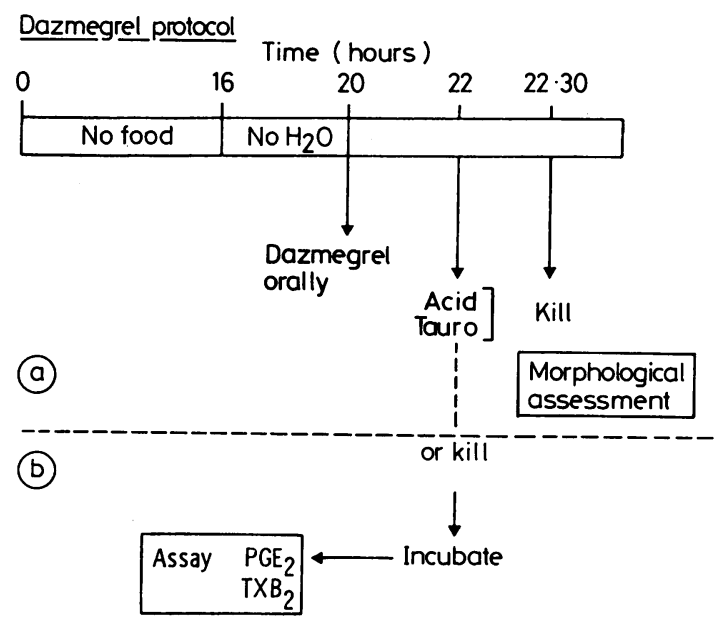

Fig. 2 Diagram illustrating the protocols followed with time (in hours) from start of starvation period shown at the top of the figure. Protocol (a) was used for all studies of morphological damage and (b) for assessments of prostanoid synthesis. neither aware of the treatments received nor the assessments of the other investigator. Complete agreement by the two observers was $76 \%$ and there were never differences of greater than one score between them. Where there was disagreement, average scores were used. Statistical analysis was by the Mann Whitney U test.

\section{THROMBOXANE AND PROSTAGLANDIN SYNTHESIS}

Eight groups of rats were treated as shown in Figure 2. They were killed (by cord transection) two hours after dosing with dazmegrel. The wall of the body of the stomach was cut into small fragments of $3-4 \mathrm{mg}$ (30-60 mg total) which were incubated at $37^{\circ} \mathrm{C}$ for 15 minutes in gassed $\left(95 \% \mathrm{O}_{2} 5 \% \mathrm{CO}_{2}\right)$ Krebs' solution on a rotating mixer. At the end of the experiment the incubated gastric fragments were removed and weighed. Indomethacin $10 \mu \mathrm{g} / \mathrm{ml}$ (final concentration) was added to the incubated supernatants which were stored at $-50^{\circ} \mathrm{C}$ until analysed (within one month). $\mathrm{TxB}_{2}$ and $\mathrm{PGE}_{2}$ were measured by radioimmunoassay of unextracted supernatant, using methods described elsewhere 1111 and antiserum kindly donated by Dr L Levine $\left(\mathrm{TxB}_{2}\right)$ or bought from the Institut Pasteur $\left(\mathrm{PGE}_{2}\right)$. The effects of dazmegrel on $\mathrm{TxB}_{2}$ and $\mathrm{PGE}_{2}$ synthesis were evaluated by $t$ test after two way analysis of variance for dose and experimental day.

\section{Results}

The rats were in good general condition before being killed and no rat died during any procedure.

\section{GASTRIC MUCOSAL DAMAGE}

The degree of mucosal damage was decreased by treatment with dazmegrel (Fig. 3). The median (range) grade of damage was $2 \cdot 5(2-4)$ with placebo $(n=8)$ and fell to $1 \cdot 5(0-3)$ with dazmegrel $1 \mathrm{mg}(n=8$, $\mathrm{p}<0.05)$ and to $1(0-3)$ with dazmegrel $5 \mathrm{mg}(\mathrm{n}=8$, $\mathrm{p}<0.01)$ and to $2(0.5-3.5)$ with dazmegrel $25 \mathrm{mg}$ $\left(n=8\right.$, NS). With $\mathrm{PGE}_{1}$ the values were $1(0-3)$, significantly lower than the comparable control values which were $2 \cdot 5(2-4)(p<0 \cdot 01)$.

\section{THROMBOXANE AND PROSTAGLANDIN} SYNTHESIS

Synthesis of $\mathrm{TXB}_{2}$ (mean and SEM) by gastric fragments from untreated rats was $84+6 \mathrm{pg} / \mathrm{mg}$ (mean and SEM). The values for $\mathrm{PGE}_{2}$ were $330+36$ $\mathrm{pg} / \mathrm{mg}$. There was dose dependant inhibition of $\mathrm{TXB}_{2}$ synthesis by dazmegrel, by $23+8 \%$ (mean + SEM) of control values $(\mathrm{p}<0.05)$ with $1 \mathrm{mg} / \mathrm{rat}$, by $34+5 \%$ $(\mathrm{p}<0.01)$ with $5 \mathrm{mg} / \mathrm{rat}$ and by $46+7 \%(\mathrm{p}<0.001)$ with $25 \mathrm{mg} / \mathrm{rat}$. The lower doses of dazmegrel had no 

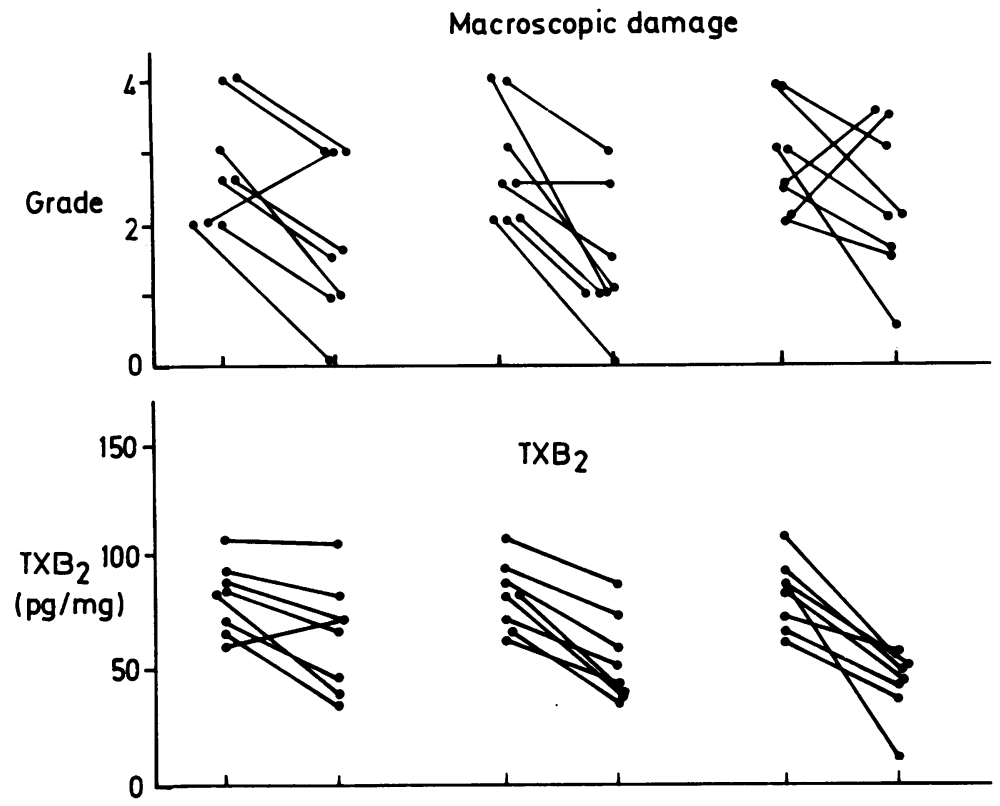

Fig. 3 Effect of three doses of dazmegrel on: Macroscopic damage after acidified taurocholate (top). Compared with placebo, damage decreased with all doses of dazmegrel (1 mg: $p<0 \cdot 05,5 \mathrm{mg}$ : p<0.01,25 mg: NS) Synthesis of $\mathrm{Tx}_{2}$ (middle). Compared with placebo $T \mathrm{XB}_{2}$ synthesis was inhibited by $1 \mathrm{mg}$ dazmegrel: $p<0.05,5$ mg dazmegrel: $p<0.01$, 25 mg dazmegrel: $p<0 \cdot 001$. Synthesis of PGE (bottom).

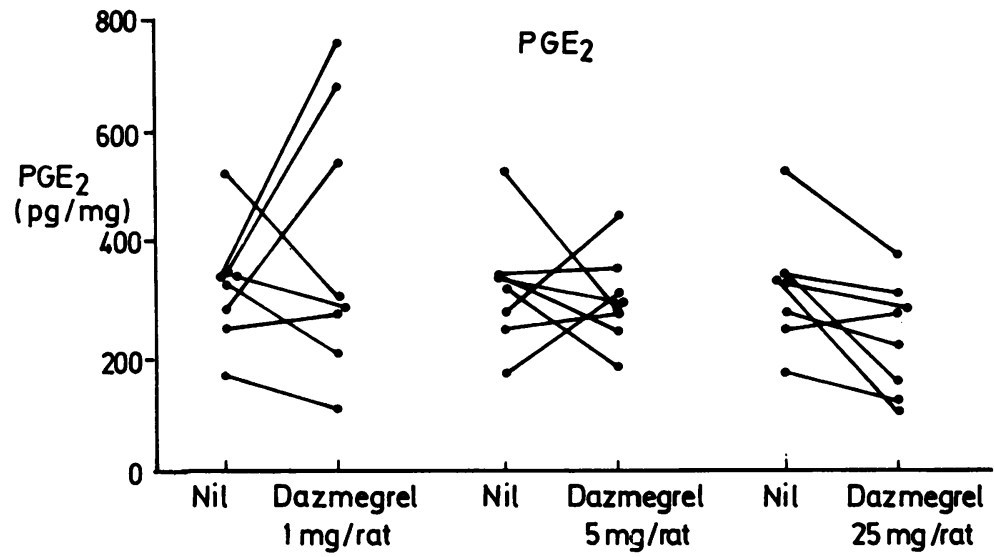
Significant inhibition was seen with $25 \mathrm{mg}$ dazmegrel only $(p<0.05)$. Individual data are shown. Line joining results from the treated rat to its untreated control.

significant effect on synthesis of $\mathrm{PGE}_{2}(122+24 \%$ control at $1 \mathrm{mg} / \mathrm{rat}$ and $102+16 \%$ control at $5 \mathrm{mg} / \mathrm{rat}$ ) but at $25 \mathrm{mg} / \mathrm{rat}$ there was $27+9 \%$ inhibition of $\mathrm{PGE}_{2}$ synthesis $(\mathrm{p}<0 \cdot 05)$.

\section{Discussion}

In this study the thromboxane synthetase inhibitor dazmegrel has been shown to afford 'cytoprotection' in an animal model of gastric mucosal damage. The second series of experiments was designed to measure the effect of dazmegrel on prostanoid synthesis at precisely the moment when acidified taurocholate would have been applied in the first series. These experiments show a dose dependent inhibition of thromboxane synthesis (measured as $\mathrm{TXB}_{2}$ ) in gastric mucosa.

These combined observations thus make it very likely that inhibition of thromboxane synthesis was the mechanism by which mucosal protection occurred. Under some circumstances dazmegrel may cause enhanced prostaglandin synthesis. ${ }^{74^{12} 13}$ This appears to be a relatively limited effect but could be important for mucosal protection. In our experiments, significant enhancement of $\mathrm{PGE}_{2}$ was not seen and, particularly when the middle dose was used, and this could not have accounted for the protection observed. We cannot say whether there was enhanced synthesis of any other prostanoid which we did not measure.

Gastric mucosal protection with two other TXSIs 
and a thromboxane receptor antagonist has now been reported in studies with rats. ${ }^{4614}$ In addition we have investigated the biochemistry of the 'cytoprotective' drug WHR2348A and shown it to be a powerful and specific inhibitor of thromboxane synthesis in the gastric mucosa. ${ }^{15}$ Taken as a whole, this evidence emphasises the importance of thromboxane synthesis in the gastric mucosa, and the therapeutic potential of TXSIs. The possibility that similar mechanisms are involved in the apparent 'cytoprotective' properties of such compounds as bismuth ${ }^{16}$ sucralfate $^{1718}$ or cimetidine ${ }^{19}$ would be worth investigating.

The precise clinical significance of our observations remains to be determined, as the contribution of 'cytoprotection' to ulcer healing by prostaglandins is currently undecided. ${ }^{1}$ Inhibition of thromboxane synthesis, however, represents a novel approach to the development of possible ulcer healing agents which warrants further investigation. Likewise the enhancement of mucosal integrity achieved by TXSIs could be of value for maintenance treatment after healing of peptic ulcers. The particular interest of dazmegrel is that it has been given to man for prolonged periods without adverse effects. Our observations therefore justify further assessment of dazmegrel's mucosal protective properties in man using established techniques to measure microscopic bleeding ${ }^{20}$ or cellular exfoliation. ${ }^{21}$

\section{References}

1 Hawkey CJ, Rampton DS. Prostaglandins in the gastrointestinal mucosa: are they important in its function, disease or treatment? Gastroenterology 1985; 89: 1162-88.

2 Robert A, Nezamis JE, Lancaster C, Hanchar A. Cytoprotection by prostaglandins in rats. Prevention of gastric necrosis produced by alcohol, $\mathrm{HCl}, \mathrm{NaOH}$, hypertonic $\mathrm{NaCl}$, and thermal injury. Gastroenterology, 1979; 77: 433-43.

3 Konturek SJ, Piastucki I, Brzozowski T, et al. Role of locally generated prostaglandins in adaptive gastric cytoprotection. Dig Dis Sci 1982; 27: 967-71.

4 Konturek SJ, Brzozowski T, Piastucki I, Radecki T, Dembinska-Kiec A. Role of prostaglandin and thromboxane biosynthesis in gastric necrosis produced by taurocholate and ethanol. Dig Dis Sci 1983; 28: 154-60.

5 Robert A, Nezamis JE, Lancaster C, Davis JP, Field SO, Hanchar AJ. Mild irritants present gastric necrosis through 'adaptive cytoprotection' mediated by prostaglandins. Am J Physiol 1983; 245: G113-21.

6 Whittle BJR. Cellular mediators in gastric damage: actions of thromboxane $A_{2}$ and its inhibitors. In: Allen A, Flemstrom G, Garner A, Silen W, Turnberg LA, eds. Mechanisms of mucosal protection in the upper gastrointestinal tract. New York: Raven, 1984: 295-302.

7 Fisher S, Struppler M, Bohlig B, Bernutz C, Liober W, Weber $P$. The influence of selective thromboxane synthetase inhibition with a novel imidazole derivated, UK 38,485 on prostanoid formation in man. Circulation 1983; 68: 821-6.

8 Barnett AH, Wakelin K, Leatherdale BA, et al. Specific thromboxane synthetase inhibition and albumin excretion in insulin-dependent diabetes. Lancet 1984; i: 1322.

9 Lorenz RL, Fischer S, Wober W, Wagner HA, Weber PC. Effects on prostanoid formation and pharmacokinetics of dazmegrel (UK-38,485), a novel thromboxane synthase inhibitor, in man. Biochem Pharmacol 1986; 35: 761-6,

10 Hawkey CJ. Evidence that prednisolone is inhibitory to the cyclooxygenase activity of human rectal mucosa. Prostaglandins 1982; 23: 397-410.

11 Hawkey CJ. Synthesis of prostaglandin $\mathrm{E}_{2}$ and thromboxane $\mathrm{B}_{2}$ and prostaglandin catabolism in gastritis and gastric ulcer. Gut 1986; 12: 1484-92.

12 Parry MJ, Randall MJ, Hawkeswood E, Cross PE, Dickinson RP. Enhanced production of prostacyclin in blood after treatment with selective thromboxane synthetase inhibitor UK-38,485. Br J Pharmacol 1982; 77: 547P.

13 Zipser RD. Effects of selective inhibition of thromboxane synthesis on renal function in humans. $A m \mathrm{~J}$ Physiol 1985; 248: F753.

14 Price CA, Pipkin G, Currington A, Davies L, Darling L, Parsons ME. Thromboxane and gastric mucosal damage. Gut 1985; 26: A1145-1146.

15 Bhaskar NK, Filipowicz B, Hawkey CJ. Inhibition of human gastric mucosal thromboxane synthesis by WHR 2348A. Br J Pharmacol 1985; 85: 268P.

16 Holroyde MJ, Yeakle C, Pepple S. Gastric cytoprotection by bismuth subsalicylate [Abstract]. Gastroenterology 1984; 86: 1116.

17 Tarnawski A, Hollander D, Krause WJ, Zipser RD, Gergely $H$. Effect of sucralfate on normal gastric mucosa. Histologic ultrastructural and functional assessment [Abstract]. Gastroenterology 1983; 84: 1331.

18 Ligumsky M, Karmeli F, Rachmilewitz D. Sucralfate stimulation of gastric $\mathrm{PGE}_{2}$ synthesis - possible mechanisms to explain its effective cytoprotective properties [Abstract]. Gastroenterology 1984; 86: 1164.

19 Branski D, Sharon P, Karmeli F, Rachmilewitz D. Effect of cimetidine on human gastric and duodenal prostanoid synthesis. Scand J Gastroenterol 1984; 19: 457-60.

20 Hawkey CJ, Simpson G, Somerville KW. Reduction by enprostil of aspirin induced blood loss from human gastric mucosa. Am J Med 1986; 81(2A): 50-3.

21 Hurst BC, Rees WDW, Garner A. Cell shedding by the stomach and duodenum. In: Allen A, Flemstrom G, Garner A, Silen W, Turnberg LA, eds. Mechanisms of gastric mucosal protection in the upper gastrointestinal tract. New York: Raven, 1984: 21-6. 